\title{
A DEFENSORIA PÚBLICA E SUA ATUAÇÃO EM TUTELAS COLETIVAS COMO MEIO DE GARANTIR O DIREITO HUMANO DE ACESSIBILIDADE E DE PROMOVER A INCLUSÃO SOCIAL DAS PESSOAS COM DEFICIÊNCIA
}

\author{
Bernardo Brito de Moraes ${ }^{1}$
}

\begin{abstract}
RESUMO
O artigo tem por objetivo explicitar como a ação da Defensoria Pública, em especial em tutelas coletivas que tratam sobre a concretização do direito humano de acessibilidade das pessoas com deficiência, influencia na obrigação do Poder Público em dar vazão às suas políticas públicas. Os métodos usados foram estudos de bibliografia, legislação e jurisprudência quanto aos temas cidadania, Defensoria Pública, acesso à justiça, pessoas com deficiência e ações coletivas. Conclui-se que tal atuação estará respaldada pela legislação, doutrina e, também, pela jurisprudência do Supremo Tribunal Federal.
\end{abstract}

PALAVRAS-CHAVE: Defensoria Pública. Tutela Coletiva. Acessibilidade. Pessoas com deficiência. Inclusão social.

\section{THE PUBLIC DEFENDER'S OFFICE AND ITS PERFORMANCE IN COLLECTIVE PROTECTION AS A WAY TO GUARANTEE THE HUMAN RIGHT OF ACCESSIBILITY AND TO PROMOTE SOCIAL INCLUSION OF PEOPLE WITH DISABILITIES}

\begin{abstract}
The objective of this research is to demonstrate how the actions of the Public Defender's Office, especially those regarding collective protection initiatives aimed at guaranteeing the human right of accessibility to the disabled, affect the State authority's obligation to direct its public policies. The methods were the analysis of bibliographic references, as well as of legislation and jurisprudence related to the subject of citizenship, Public Defence, access to justice, the disabled, and collective action. In conclusion, it was found that these actions will be safeguarded by the legislation, the doctrine, as well as by the Federal Supreme Court's jurisprudence.
\end{abstract}

KEY-WORDS: Public Defender's Office. Collective protection. Accessibility. People with disabilities. Social inclusion.

\section{INTRODUÇÃO}

\footnotetext{
${ }^{1}$ Graduado em Direito pela Universidade de Fortaleza (UNIFOR) e Especialista em Direito Processual: Grandes Transformações pela Universidade da Amazônia (UNAMA). Especializando em Direitos Fundamentais pela Universidade Federal do Pará (UFPA) e Mestrando em Direito pela Universidade Federal do Pará (UFPA). Defensor Público na Defensoria Pública do Estado do Pará (DPE-PA). E-mail: bernardo_moraes@ hotmail.com
} 
Com o intuito de dar efetividade aos postulados maiores da Carta Republicana, esta trouxe em seu art. 134 a criação da Defensoria Pública, organizada no âmbito da União, do Distrito Federal e Territórios, e, também, dos Estados. De acordo com o referido artigo, a Defensoria Pública é instituição permanente e essencial à função jurisdicional do Estado, incumbindo-lhe, como expressão e instrumento do regime democrático, fundamentalmente, a orientação jurídica, a promoção dos direitos humanos e a defesa, em todos os graus, judicial e extrajudicial, dos direitos individuais e coletivos, de forma integral e gratuita, aos necessitados, na forma do inciso LXXIV do art. $5^{\circ}$ da Constituição Federal.

Para atender tal missão, a instituição indicada deve se utilizar de todos os meios possíveis, sejam eles judiciais e/ou extrajudiciais, bem como das tutelas individuais e coletivas. Ademais, deve tal atuação ser pautada, especialmente, na promoção e efetivação dos direitos humanos.

Apesar de tal orientação e defesa dos direitos estar atrelada e vinculada ao conceito de "necessitado", verifica-se que a noção mais adequada e que melhor se coaduna com a perspectiva de dar um maior alcance e abrangência ao acesso à justiça é a que não se vincula à mera insuficiência de recursos financeiros, mas sim à insuficiência de recursos materiais, sociais e organizacionais, trazendo-se uma perspectiva de vulnerabilidade social ao caso concreto.

Assim, diante do que dispõem as Regras de Brasília sobre Acesso à Justiça das Pessoas em Condições de Vulnerabilidade, bem como do que trata a Lei $\mathrm{n}^{\circ} 13.146$, de 6 de julho de 2015, que institui a Lei Brasileira de Inclusão da Pessoa com Deficiência, também conhecida como Estatuto da Pessoa com Deficiência, pode-se perceber que o grupo de pessoas com algum tipo de deficiência encontra-se em uma situação expressa de vulnerabilidade, merecendo, assim, atenção e busca pela concreção de seus direitos por intermédio da Defensoria Pública.

Nesse ponto, questiona-se sobre qual a efetividade em se utilizar dos mecanismos de tutela coletiva para salvaguardar os direitos fundamentais estabelecidos pela $\mathrm{CF} / 88$ e os elencados em legislação ordinária, em especial no que tange à acessibilidade das pessoas com deficiência, garantindo, assim, a inclusão social do referido grupo? 
$\mathrm{O}$ artigo tem como objetivo geral explicitar como as ações coletivas, em especial as que tratam sobre a concretização de direitos humanos das pessoas com deficiência, influenciam na obrigação do Poder Público em dar vazão às suas políticas públicas.

Objetiva-se, também, de maneira específica, demonstrar e destacar a importância da ação conjunta dos grupos de pressão e da Defensoria Pública na busca da aplicação das políticas públicas, o que resulta em um aumento da educação cívica e da inclusão social por parte dos cidadãos prejudicados.

O desenvolvimento se deu por meio de estudos de bibliografia, legislação e jurisprudência quanto aos temas cidadania, Defensoria Pública, acesso à justiça, pessoas com deficiência e ações coletivas.

\section{DEFENSORIA PÚBLICA E O CONCEITO DE "NECESSITADO"}

A Constituição Federal de 1988, em seu art. $1^{\text {o }}$, traçou as características fundamentais da República Federativa do Brasil, tornando expresso que a mesma se constitui em um Estado Democrático de Direito, tendo, entre os seus fundamentos, a cidadania e a dignidade da pessoa humana.

Já em seu art. $3^{\circ}$, a Carta Maior indicou como objetivos a serem alcançados: a construção de uma sociedade livre, justa e solidária, a garantia o desenvolvimento nacional, a erradicação da pobreza e da marginalização e a redução das desigualdades sociais e regionais, bem como a promoção do bem de todos, sem preconceitos de origem, raça, sexo, cor, idade e quaisquer outras formas de discriminação.

Nesse cenário, com o intuito de dar concreção aos postulados maiores da Carta Republicana, foi prevista no art. 134 a criação da Defensoria Pública, organizada no âmbito da União, do Distrito Federal e Territórios, e também dos Estados. Nos termos do referido artigo (BRASIL, 1988, online):

A Defensoria Pública é instituição permanente, essencial à função jurisdicional do Estado, incumbindo-lhe, como expressão e instrumento do regime democrático, fundamentalmente, a orientação jurídica, a promoção dos direitos humanos e a defesa, em todos os graus, judicial e extrajudicial, dos direitos individuais e 
coletivos, de forma integral e gratuita, aos necessitados, na forma do inciso LXXIV do art. $5^{\circ}$ desta Constituição Federal.

Diante da leitura do texto constitucional, pode-se depreender que cabe à Defensoria Pública, que é constitucionalmente caracterizada como instituição permanente, essencial à função jurisdicional do Estado e expressão e instrumento do regime democrático, não só a defesa dos direitos individuais dos necessitados, mas também a tutela em caráter coletivo dos mesmos.

Para atender tal desiderato, a referida instituição pode e deve se utilizar de todos os meios possíveis, sejam eles judiciais e/ou extrajudiciais. Ademais, deve tal atuação ser pautada, especialmente, na promoção e efetivação dos direitos humanos.

Por outro lado, verifica-se que tal orientação e defesa dos direitos está atrelada e vinculada ao conceito de "necessitado", remetendo o texto constitucional ao dispositivo previsto no seu inciso LXXIV do art. $5^{\circ}$, que dispõe: "o Estado prestará assistência jurídica integral e gratuita aos que comprovarem insuficiência de recursos". (BRASIL, 1988, online)

Urge dizer que, apesar dos debates travados na doutrina e jurisprudência pátrias ao longo dos últimos anos quanto ao termo "necessitado", o conceito mais adequado e que melhor se coaduna com a perspectiva de dar maior alcance e abrangência do acesso à justiça, é o que não se vincula à mera insuficiência de recursos financeiros, mas sim à insuficiência de recursos materiais, sociais e organizacionais.

Nesse sentido, dispõe o I Relatório nacional de atuação em prol de pessoas elou grupos em condição de vulnerabilidade, organizado pela Associação Nacional dos Defensores Públicos (2015, p. 10, 21 e 23):

A Defensoria Pública não é um fim em si mesma. Existe para garantir direitos aos "necessitados" que comprovarem "insuficiência de recursos" (arts. 134 e 5, LXXIV da $\mathrm{CF}$ ), e a Constituição Federal em momento algum restringiu este público àquele com dificuldades para obtenção de recursos financeiros para fazer frente às despesas com sua subsistência - embora este seja, por excelência, o destinatário primeiro da nossa atuação. Se a Constituição não restringiu, não cabe ao intérprete fazê-lo, mormente quando se trata de direitos fundamentais e quando a legislação de regência oferece vetores outros ao trabalho de completude (como é o caso da "vulnerabilidade"). 
$[\ldots]$

A renda é o critério tradicional de identificação da pobreza, sendo de se admitir que, de fato, o baixo nível de renda pode ser causa primordial de privações em diversos níveis. Não obstante, é interessante considerar também a perspectiva de pobreza trazida pelo economista indiano Amartya Sen, que, ao estudar a questão do desenvolvimento nas suas relações com a questão da liberdade, vai considerá-la não somente como baixo nível de renda, mas como privação de capacidades básicas. Exemplificativamente, a relação entre renda e capacidade pode ser acentuadamente afetada pela idade da pessoa, pelos papéis sexuais e sociais, pela localização ou condições epidemiológicas, entre tantas outras (SEN, 2000, p. 110)

$[\ldots]$

Já o critério de vulnerabilidade, ainda que abarque a situação de pobreza, inclusive na medida das incapacidades que pode gerar, rompe com esta lógica que quantifica o ser em vez de qualificá-lo. Leva em consideração as suas reais capacidades visando a percepção de privações que podem ser de variadas ordens, e que, muitas vezes, incluindo ou não a questão da renda, se constituem em fatores da marginalização, da desigualdade e da discriminação que a República visa, expressamente, erradicar.

Ou seja, deve-se ter em perspectiva não somente o critério de renda do cidadão como parâmetro para atuação da Defensoria Pública, mas também avaliar se, no caso concreto, a pessoa ou grupo social encontra-se em situação de vulnerabilidade.

Para corroborar o Texto Maior, há exemplos na legislação infraconstitucional de que a atuação defensorial é bem mais abrangente do que a vinculada à mera insuficiência de renda do indivíduo. Veja-se o que estabelece a Lei Complementar $\mathrm{n}^{\circ}$ 80, de 12 de janeiro de 1984 (BRASIL, 1994, online):

Art. $4^{\circ}$ São funções institucionais da Defensoria Pública, dentre outras:

(...)

VII - promover ação civil pública e todas as espécies de ações capazes de propiciar a adequada tutela dos direitos difusos, coletivos ou individuais homogêneos quando o resultado da demanda puder beneficiar grupo de pessoas hipossuficientes;

(...)

XI - exercer a defesa dos interesses individuais e coletivos da criança e do adolescente, do idoso, da pessoa portadora de necessidades especiais, da mulher

Rev. Cidadania e Acesso a Justiça | e-ISSN: 2526-026X | Evento Virtual | v. 6 | n. 1 | p. 1-17 | 
vítima de violência doméstica e familiar e de outros grupos sociais vulneráveis que mereçam proteção especial do Estado;

Assim, tendo em vista esse cenário constitucional e legal do papel da Defensoria Pública, cabe a seus membros a busca e o diálogo cada vez mais próximo com a sociedade civil organizada, com o intuito de buscar, in loco, a verificação de existência e tentativa de resolução dos problemas que se impõem.

Destaca-se que o contato direto com os chamados "grupos de pressão" é de suma importância para se ter uma noção exata sobre quais os tipos de políticas públicas precisam de fato ser implementadas e também para o Poder Público ter um feedback sobre se suas ações estão ou não tendo resultados na vida da população.

Também assim entendem Orides Mezzaroba e José Fernando Vidal de Souza (2013, p. 492):

As instituições devem focar o seu olhar para a rua, enxergar as necessidades do povo e lutar para diminuir os espaços, os conflitos entre as leis criadas e os anseios daqueles que possuem expectativas decorrentes da dinâmica do convívio social. Para tanto, a luta é pela implementação do acesso à justiça, permitindo que todos possam reivindicar seus direitos ou resolver seus conflitos.

\section{PESSOAS COM DEFICIÊNCIA E SEU ENQUADRAMENTO COMO GRUPO EM SITUAÇÃO DE VULNERABILIDADE}

No que diz respeito ao grupo de pessoas em situação de vulnerabilidade, várias são as hipóteses de caracterização de tais indivíduos.

Nos dizeres de Tiago Fensterseifer (2015, p. 63-64):

De acordo com as Regras de Brasília sobre o Acesso à Justiça das Pessoas em Condições de Vulnerabilidade, aprovadas no âmbito da XIV Conferência Judicial Ibero-Americana (Brasília, 2008), consideram-se pessoas em condição de vulnerabilidade aquelas "que por razão da sua idade, gênero, estado físico ou mental, ou por circunstâncias sociais, econômicas, étnicas e/ou culturais, encontram especiais dificuldades em exercitar com plenitude perante o Sistema de Justiça os direitos reconhecidos pelo ordenamento jurídico". Do mesmo modo, consta que poderão constituir causas de vulnerabilidade, entre outras - e aí fica o registro de que

Rev. Cidadania e Acesso a Justiça | e-ISSN: 2526-026X | Evento Virtual | v. 6 | n. 1 | p. 1-17 | 
não se trata de rol taxativo, mas apenas exemplificativo -, as seguintes: a idade, a incapacidade, a pertença a comunidades indígenas ou a minorias, a vitimização, a migração e o deslocamento interno, a pobreza, o gênero e a privação de liberdade.

Diante de tais fatores, prima facie se percebe que um dos grupos sociais mais afetados pela não concretização de seus direitos, sem dúvida alguma, são as pessoas tidas com necessidades especiais ou com algum tipo de deficiência, o que enseja sua caracterização como "vulneráveis", vez que o acesso à educação, à justiça e até mesmo à locomoção se tornam extremamente difíceis e, muitas vezes, inviáveis.

A propósito, Luiz Alberto David Araújo e Vidal Serrano Nunes Júnior (2013, p. 609) exemplificam as dificuldades diárias dessas pessoas em situação de vulnerabilidade:

Como se sabe, especialmente as pessoas portadoras de deficiência visual e de locomoção sofrem terrivelmente com os obstáculos urbanos. Os "orelhões", as caixas de correios, as lixeiras, para citar alguns, representam dificuldades para o direito de locomoção das pessoas portadoras de deficiência visual. Por outro lado, as pessoas com deficiência de locomoção encontram impedimentos dos mais variados: calçadas sem rebaixamento, ônibus sem rampa para acesso de cadeiras de rodas, escada sem rampa ao lado, banheiros sem largura suficiente para a cadeira de rodas, etc.

A legislação, especialmente nos últimos anos, atenta à questão desse grupo, que, segundo dados do Instituto Brasileiro de Geografia e Estatística (2010, online), representa quase 46 milhões de brasileiros (ou $24 \%$ da população total), estipulou uma série de obrigações a serem cumpridas pelo poder público para minorar as dificuldades físicas enfrentadas pelos mesmos.

Importante, também, se citar o fato de que o cumprimento de tais políticas públicas é um fator determinante para se dar uma maior igualdade entre os membros de uma sociedade. Nos dizeres de Ronald Dworkin (2012, p. 338):

Uma comunidade política só tem força moral para criar e impor obrigações aos seus membros se os tratar com preocupação e respeito iguais; ou seja, se as suas políticas tratarem as vidas dos seus membros como igualmente importantes e respeitarem as suas responsabilidades individuais sobre as suas próprias vidas.

Rev. Cidadania e Acesso a Justiça | e-ISSN: 2526-026X | Evento Virtual | v. 6 | n. 1 | p. 1-17 | 
O referido autor vai mais longe ao indicar que tal tratamento igualitário não se trata apenas de um mero direito político, mas sim que está diretamente ligado ao princípio da dignidade da pessoa humana (DWORKIN, 2012, p. 343):

[...] apesar de as pessoas terem o direito político à preocupação e respeito iguais, segundo a concepção correta, têm um direito mais fundamental, porque mais abstrato. Têm o direito de ser tratadas com a atitude que estes debates pressupõem e refletem - o direito de serem tratadas como seres humanos cuja dignidade é fundamentalmente importante.

A primeira lei a dispor sobre tal grupo foi a Lei $\mathrm{n}^{\circ} 7.853$, de 24 de outubro de 1989 , que tratou sobre o apoio às pessoas portadoras de deficiência e sua integração social, instituindo a tutela jurisdicional de interesses coletivos ou difusos dessas pessoas, além de definir crimes e dar outras providências.

Já a Lei $n^{\circ}$ 13.146, de 6 de julho de 2015, institui a Lei Brasileira de Inclusão da Pessoa com Deficiência, também conhecida como Estatuto da Pessoa com Deficiência. Esta, em específico, será o objeto do presente estudo. Segundo o art. $2^{\circ}$, a pessoa com deficiência é considerada aquela que tem impedimento de longo prazo, seja de natureza física, mental, intelectual ou sensorial, o qual, em interação com uma ou mais barreiras, pode obstruir sua participação plena e efetiva na sociedade em igualdade de condições com as demais pessoas. $\mathrm{O}$ art. $4^{\circ}$, em plena sintonia com o postulado constitucional da isonomia, indica que todas as pessoas com deficiência têm direito à igualdade de oportunidades com as demais pessoas e não poderão sofrer nenhuma espécie de discriminação. Para se dar concretude a tais dispositivos, o art. $8^{\circ}$ deixa claro ser dever do Estado, da sociedade e da família assegurar à pessoa com deficiência, com prioridade, a efetivação dos direitos referentes à vida, à saúde, à sexualidade, à paternidade e à maternidade, à alimentação, à habitação, à educação, à profissionalização, ao trabalho, à previdência social, à habilitação e à reabilitação, ao transporte, à acessibilidade, à cultura, ao desporto, ao turismo, ao lazer, à informação, à comunicação, aos avanços científicos e tecnológicos, à dignidade, ao respeito, à liberdade, à convivência familiar e comunitária, entre outros decorrentes da Constituição Federal, da Convenção sobre os Direitos das Pessoas com Deficiência e seu Protocolo Facultativo e das leis e de outras normas que garantam seu bem-estar pessoal, social e econômico. 
Pode-se verificar, assim, que o foco principal da legislação é dar plenitude à integração social dessas pessoas, historicamente marginalizadas, seja por meio de políticas públicas de ações afirmativas, seja por meio de ações diretas do poder público.

Ademais, o tema acessibilidade é apenas um dos muitos direitos garantidos por lei, mas que necessitam ser diuturnamente buscados para terem uma real efetivação na vida de tais pessoas. E, nesse sentido, a tutela coletiva se apresenta como um dos caminhos mais céleres e eficazes para se compelir o poder público a cumprir com suas obrigações.

Além disso, importante se atentar ao fato de que, caso haja descumprimento da nova lei, estar-se-á descumprindo também simultaneamente um Tratado Internacional de Direitos Humanos, qual seja, a Convenção sobre os Direitos das Pessoas com Deficiência e seu Protocolo Facultativo. Isso porque o mesmo foi ratificado pelo Congresso Nacional por meio do Decreto Legislativo $\mathrm{n}^{\mathrm{0}} 186$, de 9 de julho de 2008, tudo em conformidade com o procedimento previsto no $\S 3^{\circ}$ do art. $5^{\circ}$ da Constituição da República Federativa do Brasil, o que fez com que ele mesmo entrasse em vigor para o Brasil, no plano jurídico externo, desde 31 de agosto de 2008, e, após a promulgação do Decreto ${ }^{\circ}$ 6.949, de 25 de agosto de 2009, deu-se o início de sua vigência no plano interno. Logo, em última instância, negar vigência aos ditames da acessibilidade é descumprir de forma direta um direito fundamental, vez que referida Convenção possui status de Emenda Constitucional.

\section{TUTELA COLETIVA COMO FORMA DE CONCRETIZAÇÃO DE DIREITOS}

A tutela coletiva dos direitos é um tema relativamente novo na seara jurídica, uma vez que ela pode ser entendida sob uma perspectiva de quebra do paradigma liberalindividualista do Direito, que regeu as relações jurídicas durante os últimos séculos. O novo modelo jurídico agora adotado é muito mais vinculado a uma moderna noção de direito social, retratado especialmente pelo princípio da dignidade da pessoa humana.

No Brasil, o marco dessa quebra de modelos jurídicos ocorre com a promulgação da Constituição Federal de 1988, que traz em seu art. $1^{\text {o }}$, inciso III, como um dos fundamentos da República Federativa do Brasil, a dignidade da pessoa humana. 
Contudo, os direitos de natureza transindividuais já começavam a possuir suas primeiras legislações específicas antes mesmo do novo marco constitucional (a exemplo da Lei da Política Nacional do Meio Ambiente - Lei no 6.938/1981 e da Lei da Ação Civil Pública - Lei no 7.347/1985), o que já demonstrava um cenário doutrinário e legislativo favorável a mudanças.

Com a $\mathrm{CF} / 88$, positivou-se a necessidade de proteção a diversos direitos de natureza coletiva, tais quais os consumeristas, sociais e ao meio ambiente. Tal fato, consequentemente, levou a uma necessária ampliação do arcabouço legal dos direitos coletivos, seja no âmbito material seja na seara processual.

Para o cumprimento de tal desiderato, também houve a necessidade de criação de uma instituição específica que pudesse dar atendimento jurídico à grande maioria da população brasileira, carente de recursos financeiros e de organização social.

Tiago Fensterseifer (2015, p. 34-35) salienta:

A criação da Defensoria Pública, como expressão desse novo paradigma jurídico, alinha-se com tal ruptura com o marco liberal-individualista e, nesse sentido, não há razão para afastar da sua atuação o manuseio dos novos instrumentos de tutela coletiva em constante aprimoramento no nosso ordenamento jurídico, pelo menos desde a edição da Lei n. 7.347/85. A Defensoria Pública não apenas está habilitada para fazer uso dos mecanismos processuais coletivos (entre eles, a ação civil pública) como, pela perspectiva do nosso Sistema de Justiça, a instituição é talvez um dos melhores exemplos do "novo capítulo" que se escreve na história políticoinstitucional brasileira, de modo a promover profundas transformações em relação ao tema do acesso à justiça (em termos individuais e coletivos), notadamente no sentido de permitir que aqueles indivíduos e grupos sociais, que por muito tempo não tiveram condições socioeconômicas e técnicas de acessar nossas Cortes de Justiça, possam fazê-lo.

Ademais, com a maior complexidade das relações sociais, principalmente a partir dos anos de 1970, com as chamadas demandas de massa, cada vez mais pessoas e grupos sociais passaram a requerer com mais urgência e necessidade a busca por seus direitos.

Tais demandas coletivas tendem, inclusive, a ajudar a sanar um pouco a crise de ineficácia e de credibilidade do sistema de justiça, que é enfrentada por décadas no Brasil. José Murilo de Carvalho (2013, p. 214-215) assim o diz: 
[...] O acesso à justiça é limitado a pequena parcela da população. A maioria ou desconhece seus direitos, ou, se os conhece, não tem condições de os fazer valer. [...] Os custos dos serviços de um bom advogado estão além da capacidade da grande maioria da população. Apesar de ser dever constitucional do Estado prestar assistência jurídica gratuita aos pobres, os defensores públicos são em número insuficiente para atender à demanda. Uma vez instaurado o processo, há o problema da demora. Os tribunais estão sempre sobrecarregados de processos, tanto nas varas cíveis como nas criminais. Uma causa leva anos para ser decidida. [...] Entende-se, então, a descrença da população na justiça e o sentimento de que ela funciona apenas para os ricos, ou antes, de que ela não funciona, pois os ricos não são punidos e os pobres não são protegidos.

Dessa feita, um dos principais instrumentos utilizados para a solução de tais litígios é a Lei da Ação Civil Pública, datada de 1985. A mesma define, em seu artigo $1^{\circ}$, que estão entre seus objetos as ações de responsabilidade por danos morais e patrimoniais causados ao meio-ambiente, ao consumidor, a bens e direitos de valor artístico, estético, histórico, turístico e paisagístico, por infração da ordem econômica, à ordem urbanística, à honra e à dignidade de grupos raciais, étnicos ou religiosos, ao patrimônio público e social e a qualquer outro interesse difuso ou coletivo. Ou seja, caso haja outros direitos difusos e coletivos que não constem expressamente do referido artigo, tal fato por si só não pode ser impedimento para o ajuizamento da ação. É o que também diz Rodolfo de Carmargo Mancuso (2014, p. 53):

É importante ter presente que o objeto da ação civil pública está, em princípio, aberto a novos e relevantes interesses metaindividuais, exegese respaldada pela própria cláusula "a qualquer outro interesse difuso ou coletivo" constante do inciso IV do art. $1^{\circ}$ da Lei 7.347/85, e, também, da parte final do art. 129, III, da CF. Não resta dúvida, pois, que os valores e interesses metaindividuais elencados no art. $1^{\circ} \mathrm{da}$ Lei 7.347/85 não estão em numerus clausus, registrando-se, ademais, tendência ampliativa a respeito, como se nota na crescente judicialização das políticas públicas, a teor do art. 37, caput, da CF, c/c art. 22 do CDC, assim superando as antigas barreiras do atos discricionários ou de natureza política.

Quanto ao rol de legitimados, o art. 5º, inciso II, da Lei $\mathrm{n}^{\circ}$ 7.347/1985 deixa claro que a Defensoria Pública está apta para ajuizar a ação principal e a ação cautelar. Ademais, devese sempre se atender à necessidade de se dar a maior amplitude possível ao acesso à justiça. Explica Carlos Eduardo Rios do Amaral (2019, online): 
Uma sociedade contemporânea deve ser o mais democrática possível. Igualmente, maior e mais livre deve ser o grau de acesso a Fóruns e Tribunais, individual ou coletivamente. Na Ação Civil Pública, em caso de dúvida sobre a legitimação para agir, sobretudo estando em jogo a dignidade da pessoa humana, devem ser abertas suas cancelas em busca da solução judicial do litígio.

Contudo, muitas vezes, quando são utilizados tais meios coletivos de tutela jurídica contra a Fazenda Pública, um dos principais e mais recorrentes argumentos do poder público para justificar sua letargia e ineficiência será o da inexistência de recursos financeiros suficientes para dar concretude aos ditames legais.

Para Gilmar Mendes (2015, p. 643):

(...) não são poucos os que se insurgem contra a própria ideia da reserva do possível como limite fático à concretização dos direitos sociais. Isso porque, apesar da realidade da escassez dos recursos para o financiamento das políticas públicas de redução de desigualdades, seria possível estabelecer prioridades entre as diversas metas a atingir, racionalizando a sua utilização, a partir da ideia de que determinados gastos, de menor premência social, podem ser diferidos, em favor de outros, reputados indispensáveis e urgentes, quando mais não seja por força do princípio da dignidade da pessoa humana, que, sendo o valor-fonte dos demais valores, está acima de quaisquer outros, acaso positivados nos textos constitucionais.

$\mathrm{E}$, aqui, não se pode perder de vista o que dispõe o $\$ 1^{\circ}$ do artigo $5^{\circ}$ da $\mathrm{CF} / 88$ (BRASIL, 1988, online): “As normas definidoras dos direitos e garantias fundamentais têm aplicação imediata".

No caso do tema tratado neste estudo, qual seja, a acessibilidade das pessoas com deficiência, pode-se perceber que a legislação pátria (Estatuto da Pessoa com Deficiência) é clara ao indicar, em seu artigo 53, que a acessibilidade é um direito que visa garantir à pessoa à pessoa com deficiência ou com mobilidade reduzida o viver de forma independente e exercer seus direitos de cidadania e de participação social.

Para garantir que tal direito possa ser cumprido, o artigo 79 dispõe que o poder público deve assegurar o acesso da pessoa com deficiência à justiça, em igualdade de oportunidades com as demais pessoas, garantindo, sempre que requeridos, adaptações e recursos de tecnologia assistiva. 
Por outro lado, para permitir o pleno acesso à justiça, e a fim de garantir a atuação da pessoa com deficiência em todo o processo judicial, o poder público também tem o dever de capacitar os membros e os servidores que atuam no Poder Judiciário, no Ministério Público, na Defensoria Pública, nos órgãos de segurança pública e no sistema penitenciário quanto aos direitos da pessoa com deficiência, além de indicar que cabe à Defensoria Pública e ao Ministério Público a tomada de todas as medidas necessárias à garantia dos direitos previstos naquela lei. (BRASIL, 2015, online)

Ora, se assim o diz a Lei, nada mais certo do que possibilitar à Defensoria Pública a possibilidade de exercício da tutela coletiva para resguardar também os direitos das pessoas com deficiência, sejam eles difusos, coletivos ou individuais homogêneos.

Ocorre, também, segundo indica Rebeca Alves de Souza Garcia (2013, p. 472):

(...) a inclusão social desse grupo tem enfrentado dificuldades, não pela inexistência de garantias legais, mas por falha da atuação do próprio Estado em cumprir seus objetivos fundamentais, além do descompromisso social e político advindo das razões histórico-culturais apresentadas.

Logo, se houver inércia por parte do Poder Executivo em dar cumprimentos às normas que tratam sobre acessibilidade, caberá a intervenção do Poder Judiciário com vias a solucionar o caso. É o que já decidiu o Supremo Tribunal Federal (BRASIL, 2013, online), quando indicou que a Constituição Federal e a Convenção Internacional sobre Direitos das Pessoas com Deficiência asseguram o direito dos portadores de necessidades especiais o acesso a prédios públicos, devendo a Administração adotar providências que o viabilizem, com possibilidade do Poder Judiciário, em situações excepcionais, determinar que a Administração Pública adote medidas assecuratórias de direitos constitucionalmente reconhecidos como essenciais, sem que isso configure violação do princípio da separação de poderes.

Assim, caso se verifique que determinada obrigação legal por parte do Estado não esteja sendo cumprida, e que referida omissão fira direitos à acessibilidade de pessoas com deficiência, deve a Defensoria Pública de imediato ajuizar uma Ação Civil Pública para combater tal agressão aos direitos desse grupo social em situação de vulnerabilidade, sendo tal atuação respaldada pela atual legislação, bem como pela melhor doutrina e também pela jurisprudência do STF.

Rev. Cidadania e Acesso a Justiça | e-ISSN: 2526-026X | Evento Virtual | v. 6 | n. 1 | p. 1-17 | 


\section{CONCLUSÃO}

A Constituição Federal de 1988, em seu art. $1^{\circ}$, trouxe entre os fundamentos da República Federativa do Brasil a cidadania e a dignidade da pessoa humana, além dispor que os objetivos a serem alcançados são a construção de uma sociedade livre, justa e solidária, a garantia o desenvolvimento nacional, a erradicação da pobreza e da marginalização e a redução das desigualdades sociais e regionais, bem como a promoção do bem de todos, sem preconceitos de origem, raça, sexo, cor, idade e quaisquer outras formas de discriminação.

Ademais, nos termos do art. 134 da Carta Maior, percebe-se que cabe à Defensoria Pública a função de defesa dos direitos individuais e coletivos dos necessitados, salientandose que a melhor doutrina entende que tal conceito de "necessitado" deve ser abalizado não somente por meio do critério de renda do cidadão, mas sim por meio de uma análise sobre se aquela pessoa ou grupo social encontra-se em situação de vulnerabilidade.

Tendo em vista a situação prática vivenciada por cerca de 46 milhões de brasileiros (ou $24 \%$ da população total) em situação de deficiência, segundo dados do Instituto Brasileiro de Geografia e Estatística (2010, online), legislações ordinárias surgiram nos últimos anos estipulando uma série de obrigações a serem cumpridas pelo poder público.

Como tema do presente trabalho, abordou-se em especial a Lei $\mathrm{n}^{\circ} 13.146$, de 6 de julho de 2015, que instituiu a Lei Brasileira de Inclusão da Pessoa com Deficiência, também conhecida como Estatuto da Pessoa com Deficiência. Segundo a legislação indicada, a pessoa com deficiência é considerada aquela que tem impedimento de longo prazo, seja de natureza física, mental, intelectual ou sensorial, o qual, em interação com uma ou mais barreiras, pode obstruir sua participação plena e efetiva na sociedade em igualdade de condições com as demais pessoas, cabendo ao Estado, à sociedade e à família assegurar à pessoa com deficiência, com prioridade, a efetivação dos direitos referentes à vida, à saúde, à sexualidade, à paternidade e à maternidade, à alimentação, à habitação, à educação, à profissionalização, ao trabalho, à previdência social, à habilitação e à reabilitação, ao transporte, à acessibilidade, à cultura, ao desporto, ao turismo, ao lazer, à informação, à comunicação, aos avanços científicos e tecnológicos, à dignidade, ao respeito, à liberdade, à convivência familiar e comunitária, entre outros decorrentes da Constituição Federal, da Convenção sobre os 
Direitos das Pessoas com Deficiência e seu Protocolo Facultativo e das leis e de outras normas que garantam seu bem-estar pessoal, social e econômico.

$\mathrm{Na}$ medida em que, historicamente, o Estado deixa de cumprir com diversas de suas obrigações legais, e no estudo se tratou especialmente quanto à acessibilidade, tem-se que será de suma importância o ajuizamento de ações coletivas por parte da Defensoria Pública, mormente a Ação Civil Pública, seja porque tal instituição está prevista como uma das legitimadas ativas na Lei $n^{\circ} 7.347 / 1985$, seja sem em virtude do $\S 1^{\circ}$ do artigo $5^{\circ}$ da $\mathrm{CF} / 88$ indicar que as normas definidoras dos direitos e garantias fundamentais têm aplicação imediata, e o direito à acessibilidade é um deles.

Ademais, tal atuação estará respaldada pela atual legislação, bem como pela melhor doutrina e também pela jurisprudência do STF, que já se posicionou no sentido que o poder público não pode se utilizar do princípio da reserva do possível para não dar plenitude e assegurar a observância de direitos constitucionalmente garantidos.

\section{REFERÊNCIAS}

AMARAL, Carlos Eduardo Rios do. Da legitimidade da Defensoria Pública para as ações coletivas. Disponível em: https://www.anadep.org.br/wtk/pagina/materia?id=15881, Acesso em: 16 out. 2019.

ARAUJO, Luiz Alberto David; NUNES JUNIOR, Vidal Serrano. Curso de Direito Constitucional. 18. ed. São Paulo: Verbatim, 2013.

ARENHART, Sérgio Cruz. A tutela coletiva de interesses individuais: para além da proteção dos interesses individuais homogêneos. 2. ed. São Paulo: Revista dos Tribunais, 2014.

ASSOCIAÇÃO NACIONAL DOS DEFENSORES PÚBLICOS. I relatório nacional de atuação em prol de pessoas e/ou grupos em condição de vulnerabilidade. Organização: Glauce Franco; Patrícia Magno. Brasília: ANADEP, 2015. 125 p., ISBN 978-85-69001-00-3. Disponível em: https://www.anadep.org.br/wtksite/Livro_Relat_rio_de_Atua_es.pdf, Acesso em: 11 jul. 2015.

BRANCO, Paulo Gustavo Gonet; MENDES, Gilmar Ferreira. Curso de Direito Constitucional. 10. ed. Saraiva: São Paulo, 2015.

Rev. Cidadania e Acesso a Justiça | e-ISSN: 2526-026X | Evento Virtual | v. 6 | n. 1 | p. 1-17 | 
BRASIL. [Constituição (1988)]. Constituição da República Federativa do Brasil. Brasília, DF: Presidência da República, [1988]. Disponível em: http://www.planalto.gov.br/ccivil_03/Constituicao/Constituicao.htm, Acesso em: 20 out. 2019.

BRASIL. Lei Complementar $\mathbf{n}^{\circ}$ 80, de 12 de janeiro de 1994. Organiza a Defensoria Pública da União, do Distrito Federal e dos Territórios e prescreve normas gerais para sua organização nos Estados, e dá outras providências. Brasília, DF: Presidência da República, [1994]. Disponível em: http://www.planalto.gov.br/ccivil_03/Leis/LCP/Lcp80.htm, Acesso em: 20 out. 2019.

BRASIL. Lei $\mathbf{n}^{0}$ 7.347, de 24 de julho de 1985. Disciplina a ação civil pública de responsabilidade por danos causados ao meio-ambiente, ao consumidor, a bens e direitos de valor artístico, estético, histórico, turístico e paisagístico (VETADO) e dá outras providências. Brasília, DF: Presidência da República, [1985]. Disponível em: http://www.planalto.gov.br/ccivil_03/Leis/L7347orig.htm, Acesso em: 20 out. 2019.

BRASIL. Lei n. 13.146, de 6 de julho de 2015. Institui a Lei Brasileira de Inclusão da Pessoa com Deficiência (Estatuto da Pessoa com Deficiência). Brasília, DF: Presidência da República, [2015]. Disponível em: http://www.planalto.gov.br/CCIVIL_03/_Ato20152018/2015/Lei/L13146.htm, Acesso em: 20 out. 2019.

BRASIL. Supremo Tribunal Federal (1. Turma). Recurso Extraordinário 440.028/SP, Prédio público - Portador de necessidade especial - Acesso. A Constituição de 1988, a Convenção Internacional sobre Direitos das Pessoas com Deficiência e as Leis $n^{0} 7.853 / 89$ federal - $\mathrm{n}^{\circ}$ 5.500/86 e n $\mathrm{n}^{\mathrm{0}}$ 9.086/95 - estas duas do Estado de São Paulo - asseguram o direito dos portadores de necessidades especiais ao acesso a prédios públicos, devendo a Administração adotar providências que o viabilizem. Recorrente: Ministério Público do Estado de São Paulo. Recorrido: Estado de São Paulo. Relator: Min. Marco Aurélio, de 29 de outubro de 2013. Disponível em: http://portal.stf.jus.br/processos/downloadPeca.asp?id=186421043\&ext=.pdf, Acesso em: 30 abr. 2020.

CARVAlHO, José Murilo de. Cidadania no Brasil: o longo caminho. 17. ed. Rio de Janeiro: Civilização Brasileira, 2013.

DWORKIN, Ronald. Justiça para Ouriços. Coimbra: Almedina. 2012. 
FENSTERSEIFER, Tiago. Defensoria Pública, direitos fundamentais e ação civil pública: a tutela coletiva dos direitos fundamentais (liberais, sociais e ecológicos) dos indivíduos e grupos necessitados. São Paulo: Saraiva, 2015.

GARCIA, Rebeca Laves de Souza. A inclusão da pessoa com deficiência: aplicabilidade das ações afirmativas para extinção de barreiras histórico-culturais. In: SMANIO, Gianpaolo Poggio; BERTOLIN, Patrícia Tuma Martins (org.). O direito e as políticas públicas no Brasil. São Paulo: Atlas, 2013.

INSTITUTO BRASILEIRO DE GEOGRAFIA E ESTATÍSTICA. Censo Demográfico de 2010. Disponível em: https://educa.ibge.gov.br/jovens/conheca-o-brasil/populacao/20551pessoas-com-deficiencia.html, Acesso em: 30 abr. 2020.

MANCUSO, Rodolfo de Camargo. Ação Civil Pública: em defesa do meio ambiente, do patrimônio cultural e dos consumidores - Lei 7.347/1985 e legislação complementar. 13. ed. São Paulo: Revista dos Tribunais, 2014.

MEZZAROBA, Orides; SOUZA, José Fernando Vidal de. O Positivismo jurídico: em busca de um novo paradigma emancipador a partir dos conflitos sociais no Brasil. In: ALEXY, Robert; BAEZ, Narciso Leandro Xavier; HAHN, Paulo; SANDKÜHLER, Hans Jörg (org.). Níveis de efetivação dos direitos fundamentais civis e sociais: um diálogo Brasil e Alemanha. Joaçaba: Editora Unoesc, 2013. 